\title{
Availability of Partially Milled Rice as a Daily Source of $\boldsymbol{\gamma}$-Aminobutyric Acid
}

\author{
Keiko IWAKI* and Yoshimi KITADA \\ Faculty of Health Science, Kio University, 4-2-2 Umaminaka, Koryo-cho, Kitakatsuragi-gun, Nara 635-0832, Japan
}

Received January 17, 2006; Accepted October 10, 2006

\begin{abstract}
We investigated the use of a high-performance liquid chromatography (HPLC) with o-phthalaldehyde fluorescence detection to simultaneously quantify $\gamma$-Aminobutyric acid (GABA), glutamate and alanine. Using this method, the column (COSMOSIL $5 \mathrm{C}_{18}$-MS-II, $4.6 \mathrm{~mm}$ i.d. $\times 15 \mathrm{~cm}$ ) was eluted using a linear gradient of acetonitrile and $5 \mathrm{mM}$ citrate buffer $(\mathrm{pH} \mathrm{6.0)}$. The GABA contents of both milled and cooked rice samples were measured, with a gradual decrease observed as the rice was milled in raw rice. However, GABA content was markedly diminished due to washing in rice milled for a longer period. In less milled rice, the GABA and glutamate contents increased when the rice was cooked without washing. As a result, the GABA content of cooked under-milled rice was twice that of cooked well-milled rice available in the market, and three times greater for under-milled cooked rice without washing. These findings revealed that partially milled rice could be utilized as a daily source of GABA.
\end{abstract}

Keywords: $\gamma$-aminobutyric acid, HPLC with a fluorescence detector, under-milled rice, cooked rice

\section{Introduction}

GABA is the most widespread inhibitory neurotransmitter (Bronstein and Cummings, 2001). GABA is expected to have a hypotensive effect on blood pressure and to be involved in alleviating mental stress. It has been shown that the GABA in rice germ could allay anxiety during menopause and in the elderly (Okada et al., 2000). Subjects with high normal blood pressure were given fermented milk containing GABA for 12 weeks, and it was demonstrated that their blood pressure was significantly lowered by this treatment (Kajimoto et al., 2004). Recent1y, in Japan, some foods supplemented with GABA have gained popularity. However, GABA is naturally synthesized by the action of a decarboxylase on glutamate, which is reversibly transformed into alanine by a transaminase. Rice germ and bran contain glutamate decarboxylase. Incubation with glutamate resulted in the immediate production of GABA (Ohtsubo et al., 2000). Determination of the GABA content of brown rice, germinated brown rice, and germinated unhulled rice revealed that the GABA content of the germinated types was higher than that of brown rice (Ohisa et al., 2003). Germinated brown rice, or hatsuga-genmai, has recently been introduced onto the market. It can be cooked well with well-milled rice and has a GABA content that is several times higher than that of well-milled rice. Thus, it is expected that a daily diet of cooked rice combined with 10\% hatsuga-genmai can effectively increase the GABA intake. Conversely, brown rice also contains more GABA than well-milled rice but it needs to be soaked in water for more than 2-3 hours before boiling, and its palatability is low, which means that it is general-

* To whom correspondence should be addressed.

E-mail: k.iwaki@kio.ac.jp 1y avoided. However, partially-milled brown rice can absorb water over a short period of time and tastes as good as well-milled rice. In 2005, we reported that the GABA content of rice samples could be measured by HPLC with fluorescence detection and that the GABA content of rice milled for a shorter period was higher than that of types that had been milled for longer. To simultaneously quantify GABA, glutamate, and alanine, we analyzed the rice samples using this HPLC method using $o$-phthalaldehyde fluorescence instead of fluorescamine. We found that partially milled rice could be utilized as a daily source of GABA.

\section{Materials and Methods}

Rice samples Brown rice (Oryza sativa L.; $450 \mathrm{~g}$; Hinohikari from Nara Prefecture grown in 2004) was milled for 1.5, 2, 3, and 4.5 min using a milling machine (Tiger Co. RSD-A), and labeled as under-milled, well-milled 1, wellmilled 2, and over-milled rice, respectively. Rice samples were stored at $4^{\circ} \mathrm{C}$ until use.

Chemicals o-Phthalaldehyde (OPA) and 2-mercaptoethanol were purchased from Wako Co. All other chemicals were of analytical grade. The OPA reagent used for precolumn derivatization of HPLC was prepared according to the method of Goto et al. (1993). Twenty milligrams of OPA was dissolved in $3 \mathrm{ml}$ acetonitrile, and $7 \mathrm{ml}$ $0.1 \mathrm{M}$ borate buffer ( $\mathrm{pH}$ 9.0) was added. This was kept under cold storage conditions overnight and filtered through a $0.45 \mu \mathrm{m} \times 20 \mathrm{~mm}$ i.d. RC-membrane filter (Sartorius $A G)$.

Cooking method The cooking method used in this experiment was in accordance with that reported in a previous paper (Iwaki et al., 2005, in Japanese). Rice (462 g) was washed thrice with $700 \mathrm{ml}$ water, drained, and water was again added to give a total weight of $1132 \mathrm{~g}$. 
It was cooked in a rice cooker (Tiger Co. $\mathrm{IH}$ rice cooker JKA-A100HU, Japan) under conditions similar to those used for hakumai-futsudaki and was labeled as washed and cooked rice. Rice that was cooked without washing was labeled "non-washed" and "cooked" rice. After cooking, a sample of cooked rice was immediately collected from the central portion of the cooked rice.

Measurement of the moisture content Before cooking, the rice was ground into pieces using a mill (Iwatani Co. IFM-700G, Japan). Subsequently, $5 \mathrm{~g}$ was weighed, placed within an aluminum foil receptacle, and dried at $135^{\circ} \mathrm{C}$ for $3 \mathrm{~h}$ to measure the moisture content. A similar procedure was followed for the cooked rice sample, except that $10 \mathrm{~g}$ of cooked rice was weighed into an aluminum foil vessel and wrapped within the aluminum foil. The aluminum foil was then unfolded to dry at $135^{\circ} \mathrm{C}$ for $3 \mathrm{~h}$.

Analyses of several rice characteristics The weight of 1000 rice grains was estimated using the method employed by the National Food Research Institute (Ministry of Agriculture and Forestry, 1969). The color of the surface of the rice grains was measured using a spectrophotometer (Nippondenshoku Co. SE 2000, Japan), as reported previously. Rice grains were placed within a transparent acrylic cylinder ( $31 \mathrm{~mm}$ diameter, $13 \mathrm{~mm}$ height) to measure the reflected light (Lab value) when the gauge diameter was $30 \mathrm{~mm}$.

Extract preparation Rice powder (5g) was homogenized $(15000 \mathrm{rpm} \times 2 \mathrm{~min})$ with $25 \mathrm{ml}$ of $75 \%$ ethanol in a homogenizer (IKA Works T25 Basic 81), and the homogenate was filtered through a No. 5B filter paper. The residue was extracted thrice with $25 \mathrm{ml}$ of $75 \%$ ethanol, and the volume of the collected filtrate was made up to $100 \mathrm{ml}$ with $75 \%$ ethanol. In the case of cooked rice, approximately $18 \mathrm{ml}$ of $99.5 \%$ ethanol was added to a $10 \mathrm{~g}$ sample, which is equivalent to $5 \mathrm{~g}$ of raw rice (Iwaki et al., 2005). The other procedures were the same as those performed in the case of rice powder.

Analysis of GABA content The HPLC conditions were the same as those reported by Goto et al. (1993). The sample was prepared by mixing $20 \mu 1$ of the extract solution, $200 \mu 1$ of the OPA reagent, and $200 \mu 1$ of 2 -mercaptoethanol solution [ $50 \mu$ l of 2 -mercaptoethanol in 0.1 $\mathrm{M}$ borate buffer ( $\mathrm{pH} 9.0)]$ in a phial; $10 \mu 1$ of the mixture was then immediately injected into the HPLC column (COSMOSIL 5 $\mathrm{C}_{18}$-MS-II, $4.6 \mathrm{~mm}$ i.d. $\times 15 \mathrm{~cm}$ ). The method used a linear acetonitrile gradient (solution A) and $5 \mathrm{mM}$ citrate buffer ( $\mathrm{pH}$ 6.0) (solution B). This operation was performed mechanically (Shimadzu Co. LC-10AD with RF-10A, Japan). The mobile phase comprised 15\% solution $\mathrm{A}$ and $85 \%$ solution $\mathrm{B}$ at $0 \mathrm{~min}, 16.5 \%$ solution $\mathrm{A}$ and $83.5 \%$ solution $\mathrm{B}$ at $15 \mathrm{~min}, 30 \%$ solution $\mathrm{A}$ and $70 \%$ solution B from 35 to $40 \mathrm{~min}$, and 15\% solution A and $85 \%$ solution $\mathrm{B}$ for $10 \mathrm{~min}$. The flow rate and column temperature were set to $0.8 \mathrm{ml} / \mathrm{min}$ and $40^{\circ} \mathrm{C}$, respectively. The fluorescence detector was set at Ex. $340 \mathrm{~nm}$ and Em. $450 \mathrm{~nm}$.

\section{Results and Discussion}

Elution pattern of the rice extract In order to investigate the effect of concentration and $\mathrm{pH}$ of the citrate buffer on peak height, the concentration and $\mathrm{pH}$ were adjusted to 5 to $20 \mathrm{mM}$ and 5.0 to 9.0 , respectively. The peaks were most pronounced when the concentration of citrate buffer was $5 \mathrm{mM}$; however, the peaks were independent of the $\mathrm{pH}$. Based on these findings, $5 \mathrm{mM}$ citrate buffer ( $\mathrm{pH}$ 6.0) was used as the mobile phase. The elution patterns of standard GABA $(1 \mu \mathrm{g} / \mathrm{ml})$ and the undermilled rice extract are shown in Fig. 1. The major peaks from the under-milled rice extract were confirmed to correspond to L-glutamate (7.27 min), L-asparagine (11.74 min), L-arginine (13.59 min), L-alanine (29.72 min), GABA (31.97 $\mathrm{min})$, and L-tyrosine $(33.51 \mathrm{~min})$. The contents of the other amino acids were comparatively lower. These results agreed with previously reported results on the composition of amino acids in cooked rice (Oryza sativa L., Koshihikari, harvested from Kyoto Prefecture in 2003) that had been obtained using an amino acid analyzer (Hitachi Co. L-8500) (Iwaki, unpublished). L-Glutamate and L-alanine are closely related to GABA biosynthesis

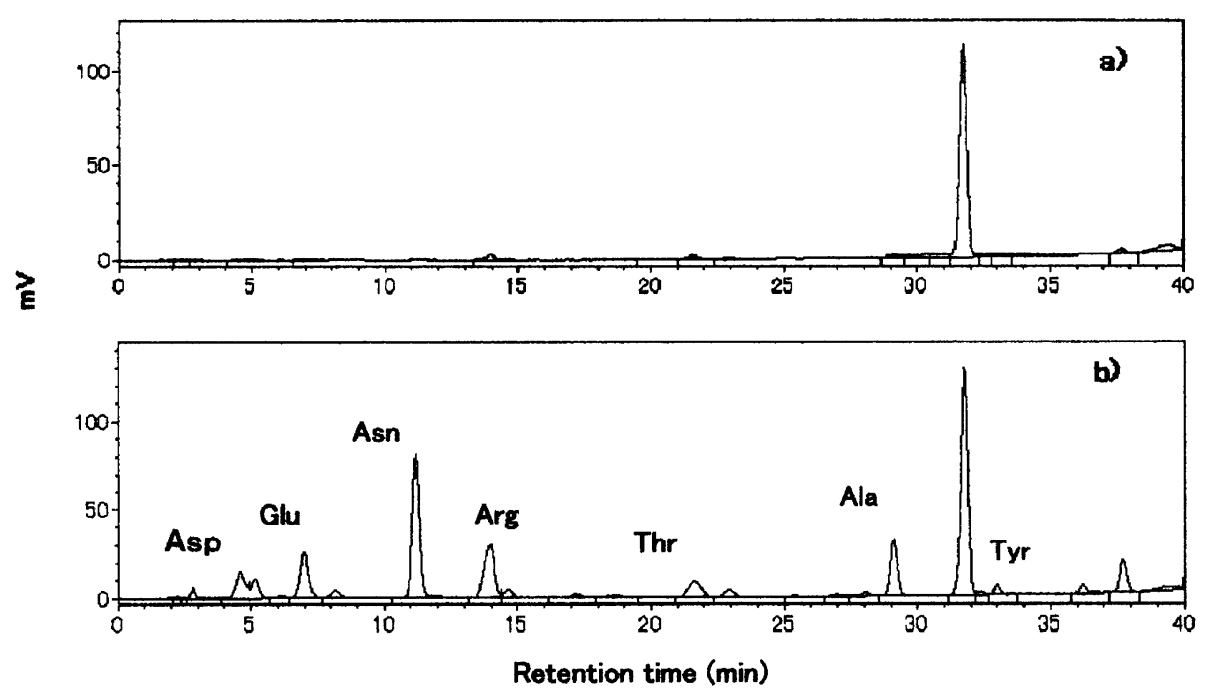

Fig. 1. Chromatograms of GABA standard $(1 \mu \mathrm{g} / \mathrm{ml})$ (a) and under-milled rice extract (b). 
Table 1. Some characteristics and GABA content of milled rice.

\begin{tabular}{|c|c|c|c|c|c|c|c|c|}
\hline \multirow[b]{2}{*}{ Sample } & \multirow{2}{*}{$\begin{array}{c}\text { Milling } \\
\text { yield(\%) }\end{array}$} & \multirow{2}{*}{$\begin{array}{c}\text { Weight of } \\
1000 \text { grain }(\mathrm{g})\end{array}$} & \multirow{2}{*}{$\begin{array}{l}\text { Remain of } \\
\text { germ (\%) }\end{array}$} & \multirow{2}{*}{$\begin{array}{l}\text { Content of } \\
\text { water }(\%)\end{array}$} & \multicolumn{3}{|c|}{ Color of grain surface } & \multirow{2}{*}{$\begin{array}{c}\text { Content of } \\
\text { GABA } \\
(\mu \mathrm{g} / \mathrm{g} \cdot \mathrm{dry})\end{array}$} \\
\hline & & & & & $L$ value & a value & $\mathrm{b}$ value & \\
\hline under-milled & 94.0 & $20.27 \pm 0.15^{a}$ & $39.59 \pm 5.59^{a}$ & $15.89 \pm 0.10$ & $65.38 \pm 0.41^{a}$ & $-0.22 \pm 0.11$ & $19.52 \pm 0.34$ & $27.71 \pm 1.40^{a}$ \\
\hline well-milled 1 & 92.4 & $19.73 \pm 0.01^{b}$ & $12.20 \pm 0.93^{b}$ & $16.06 \pm 0.12$ & $66.92 \pm 0.51^{b}$ & $-1.36 \pm 0.07$ & $17.70 \pm 0.18$ & $22.48 \pm 1.16^{\mathrm{b}}$ \\
\hline well-milled 2 & 91.3 & $19.56 \pm 0.13^{b}$ & $6.97 \pm 0.60^{\circ}$ & $15.86 \pm 0.12$ & $69.25 \pm 0.67^{\circ}$ & $-1.76 \pm 0.04$ & $16.88 \pm 0.36$ & $20.87 \pm 2.55^{b c}$ \\
\hline over-milled & 88.8 & $19.26 \pm 0.01^{\mathrm{b}}$ & $1.80 \pm 0.49^{d}$ & $15.72 \pm 0.05$ & $71.22 \pm 0.36^{d}$ & $-2.27 \pm 0.04$ & $14.78 \pm 0.10$ & $17.64 \pm 1.47^{\circ}$ \\
\hline
\end{tabular}

Each value represents the mean \pm S.D. calculated from 3 determinations.

Means in a column without a common letter differ, $\mathrm{P}<0.05$.

and were measured with GABA in order to plot the following calibration curves: L-glutamate $(\mathrm{y}=676475 \mathrm{x}+$ 29411, $\left.\mathrm{R}^{2}=0.9992\right), \quad$-alanine $\left(\mathrm{y}=759652 \mathrm{x}+57676, \quad \mathrm{R}^{2}=\right.$ 0.9989), and GABA $\left(y=1218500 x+19236, R^{2}=0.9994\right)$. The limits of detection for GABA and the other amino acids were $0.05 \mu \mathrm{g} / \mathrm{ml}$ and $0.1 \mu \mathrm{g} / \mathrm{ml}$, respectively; whereas, the detection limits of were $0.02 \mu \mathrm{g} / \mathrm{ml}$ and $0.05 \mu \mathrm{g} / \mathrm{ml}$, respectively.

Some characteristics and the GABA content of rice samples A few characteristics and the GABA content of four rice samples are shown in Table 1 . In a previous paper, the milled rice samples were over-milled due to the use of a large milling machine. However, a smaller milling machine was used in this study and the milling yields of the four samples were $94.0 \%, 92.4 \%, 91.3 \%$, and $88.8 \%$, respectively. In general, the milling yield of well-milled rice derived from brown rice was approximately $92 \%$. Further, the samples were labeled as being "under-milled", "well-milled 1", "well-milled 2", and "over-milled" rice, while the identically labeled samples reported in the previous paper were labeled as "more milled".

The weight of 1000 grains was observed to decrease in proportion to the milling yield. The residual amounts of the germs present in all the samples were significantly different. The color of the grain surface indicated that the L-value increased in proportion to the milling yield, whereas the a- and the b-values decreased. The color of rice gradually became brighter and tinged with green. However, it changed to pale yellow in proportion to the milling yield. The GABA content was significantly higher in under-milled than in well-milled 1 rice, and it was also higher in well-milled 1 than in over-milled rice. There was no significant difference between well-milled 1 and well-milled 2 rice. The relationship between GABA content and the weight of 1000 grains is shown in Fig. 2 along with additional results from a previous paper. Although the harvest year of the two samples was differed, the GABA content was in direct proportion to the weight of 1000 grains. This showed that the GABA content gradually decreased as the rice was milled.

Water and GABA content of cooked rice The water and GABA contents of cooked rice are shown in Table 2. Although there was no significant difference in the water content of cooked rice, the water content of washed, under-milled rice was slightly higher than that of the other samples. In washed and cooked rice samples, the GABA content was significantly higher in under-milled

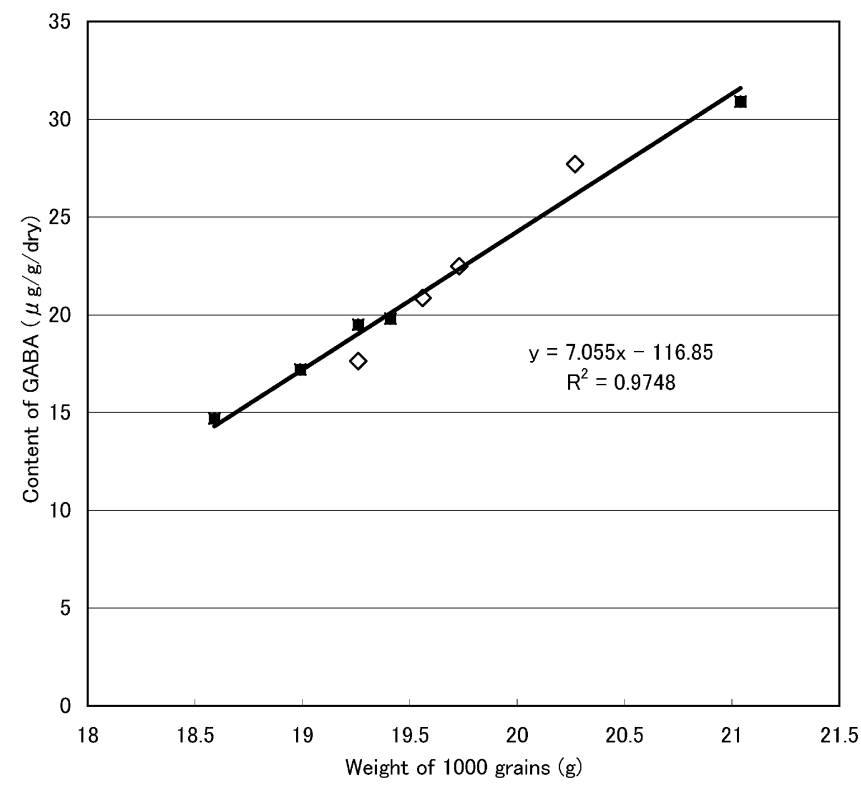

Fig. 2. Correlation between GABA content and weight of 1000 grains of Hinohikari harvested in $2004(\diamond)$ and 2003 in the previous paper $(\boldsymbol{\square})$.

Table 2. Contents of water and GABA in cooked rice.

\begin{tabular}{lcccc}
\hline \multicolumn{1}{c}{ Sample } & \multicolumn{2}{c}{ Washed } & \multicolumn{2}{c}{ Non-washed } \\
& Water $(\%)$ & GABA $(\mu \mathrm{g} / \mathrm{g} \cdot \mathrm{dry})$ & Water $(\%)$ & $\mathrm{GABA}(\mu \mathrm{g} / \mathrm{g} \cdot \mathrm{dry})$ \\
\hline under-milled & $63.02 \pm 1.10$ & $28.83 \pm 0.10^{\mathrm{a}}$ & $61.42 \pm 1.28$ & $37.96 \pm 0.68^{\mathrm{a}}$ \\
well-milled 1 & $61.45 \pm 0.23$ & $20.97 \pm 1.70^{\mathrm{b}}$ & $59.55 \pm 0.90$ & $27.15 \pm 0.51^{\mathrm{b}}$ \\
well-milled 2 & $60.22 \pm 0.50$ & $12.12 \pm 0.18^{\mathrm{c}}$ & $59.36 \pm 0.27$ & $19.50 \pm 0.79^{\mathrm{c}}$ \\
over-milled & $61.17 \pm 0.79$ & $11.30 \pm 0.39^{\mathrm{c}}$ & $61.68 \pm 0.61$ & $17.52 \pm 1.46^{\mathrm{c}}$ \\
\hline
\end{tabular}

Each value represents the mean \pm S.D. calculated from 3 determinations. Means in a column without a common letter differ, $\mathrm{P}<0.01$.

than in well-milled 1 rice, and it was also higher in wellmilled 1 than in well-milled 2 rice. The GABA content of under-milled rice was 2.6 times that of over-milled rice. A comparison of the GABA contents of washed and cooked rice with that of raw rice indicated that it was barely altered by washing and cooking in under-milled rice. Conversely, however, it was reduced to $58 \%$ and $64 \%$ in well-milled 2 and over-milled rice, respectively. On the other hand, the GABA content was considerably higher in non-washed and cooked rice than it was in washed and cooked rice. A comparison of the GABA content in non-washed and cooked rice with that of raw rice suggested that it was remained relatively constant in well-milled 2 and over-milled rice but increased markedly 


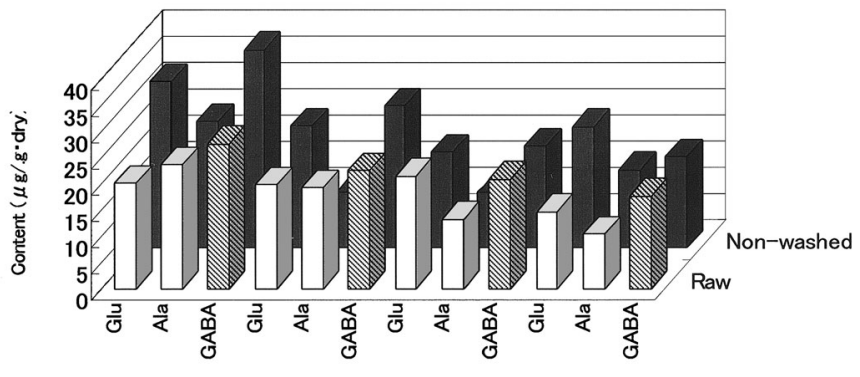

Under-milled Well-milled 1 Well-milled 2 Over-milled

Fig. 3. Contents of GABA, glutamate and alanine in raw rice and non-washed cooked rice.

in under-milled and well-milled 1 rice. This suggested that the GABA content decreased primarily due to washing in well-milled rice such as over-milled and well-milled 2 rice. However, in less well milled rice such as undermilled and well-milled 1 rice, the loss of GABA due to washing was either low or the production of GABA while cooking was equal to the amount lost. The contents of GABA, glutamate, and alanine in raw and non-washed cooked rice are shown in Fig. 3. Glutamate was converted to GABA by a glutamate decarboxylase, and alanine was produced by a transfer reaction of amine with pyruvate (Sanga T., 2002). In under-milled and wellmilled 1 rice, the GABA and glutamate contents markedly increased, while that of alanine increased only slightly. This indicated that more glutamate was produced than was lost due to conversion to GABA by a glutamate decarboxylase in under-milled and well-milled 1 rice. In over-milled rice, the glutamate and alanine contents increased markedly but that of GABA changed only slightly. This indicated that the glutamate produced during cooking was converted to alanine.

In conclusion, the GABA content in raw rice gradually decreased in proportion to the milling yield. With regard to washed and cooked rice, the GABA content decreased primarily during cooking in more milled rice. The GABA content of non-washed less milled and cooked rice was significantly higher than that of the more milled varieties. As a result, the GABA content of cooked un- der-milled rice was twice that of cooked well-milled rice available on the market, that of cooked under-milled rice without washing was three times higher still. These findings revealed that partially milled rice without washing could be utilized as a daily source of GABA.

Acknowledgements This study was partly supported by Tiger Co., Osaka.

\section{References}

Bronstein Y.I. and Cummings J.L. (2001). Neurochemistry of Frontal - Subcortical Circuits. In "Frontal-Subcortical Circuits in Psychiatric and Neurological Disorders," ed. by Lichter D.G. and Cummings J.L., The Guilford Press, New York and London, 63-66.

Goto T., Horie H. and Muakai T. (1993). Analysis of major amino acids in green tea by high-performance liquid chromatography coupled with OPA precolumn derivatization. Chagyo kenkyu hokoku, 77, 29-33 (in Japanese).

Kajimoto O., Hirata H., Nakagawa S., Kajimoto Y., Hayakawa K. and Kimura M. (2004). Hypotensive effect of fermented milk containing $\gamma$-aminobutyric acid (GABA) in subjects with high normal blood pressure. Nippon Shokuhin Kagaku Kogaku Kaishi, 51, 79-86 (in Japanese).

Iwaki K., Matsumura Y. and Kitada Y. (2005). Determination of $\gamma$-aminobutyric acid in partially milled and cooked rice samples by high-performance liquid chromatography with fluorescence detection. J. Cookery Science of Japan (Nippon chorikagakukai-shi), 38, 231-235 (in Japanese).

Ohisa N., Ohno T. and Mori K. (2003). Free amino acid and $\gamma$ aminobutyric acid contents of germinated rice. Nippon Shokuhin Kagaku Kogaku Kaishi, 50, 316-318 (in Japanese).

Ohtsubo S., Asano S., Sato K. and Matsumoto I. (2000). Enzymatic production of $\gamma$-aminobutyric acid using rice (Oryza sativa) germ. Food Sci. Technol. Res., 6, 208-211 (in Japanese).

Okada T., Sugishita T., Murakami T., Murai H., Saikusa T., Horino T., Onoda A., Kajimoto O., Takahashi R. and Takahashi T. (2000). Effect of the defatted rice germ enriched with GABA for sleeplessness, depression, autonomic disorder by oral administration. Nippon Shokuhin Kagaku Kogaku Kaishi, 47, 596-603 (in Japanese).

Sanga T. (2002). Production and metabolism of $\gamma$-aminobutyric acid. In "Harper's Biochemistry the $25^{\text {th }}$ edition," ed. by Murray R.K., Granner D.K., Mayes P.A. and Rodwell V.W., Maruzen Inc., Tokyo, 387-388 (in Japanese). 